\title{
De la energía-saber a la inteligencia social. Nuevos desafíos nuestramericanos en la producción, circulación y consumo de la información y el conocimiento
}

Recepción: 20 - 10 - 2015 / Aceptación: 24 - 11 - 2015

José Carlos Bonino

\section{Resumen \\ El presente artículo pone en discusión los fundamentos políticos y culturales de la construcción de la comunicación, la información y la propaganda, contextualizándolos en una crisis paradigmática en nuestro espacio-tiempo. Discute sobre la coexistencia de dos cosmovisiones en nuestra realidad, una hegemónica y otra subalterna que conviven en tensión dialéctica sin paridad de condiciones. Pone al centro del debate la necesidad de construir nuevo conocimiento a partir de nuestras circunstancias geopolíticas, geoeconómicas y geoculturales, para los nuevos tiempos.}

Palabras claves: Información, comunicación, propaganda, cosmovisión, conocimiento, sabiduría, epistemología, geopolítica, geoeconómia, geocultura, dialogo de saberes.

\begin{abstract}
This essay gives a discussion about political and cultural basics of communication, information and advertising building, contextualizing within a paradigmatic crisis in our space - time. It argue about two visions in our reality, one hegemonic and other subaltern, both coexist in dialectical tension without parity conditions. State the center of the debate the need to build new knowledge based on our geopolitical, economic and cultural circumstances.
\end{abstract}

Key words: Information, comunication, advertising, worldview, Knowledge, wisdom, epistemology, geopolítics, geoeconomy, geoculture, knowledge dialogue

\section{Introducción}

En casi toda Nuestramérica en la ultima década y media se han vivido transformaciones revolucionarias gracias a esa energía social liberadora que todos los pueblos poseen transitando de la energíasocial al poder político.

En la actualidad estamos enfrentando nuevos desafíos, en el contexto de la reducción de los precios de las materias primas y del resurgir de las derechas pos neoliberales, aliadas a los poderes foráneos, que pujan por la restauración conservadora en Nuestramérica. Vivimos una coyuntura de grandes cambios en materia de producción, circulación y consumo de la información y el conocimiento, dos ejes fundamentales sobre los cuales se jugará mucho del futuro de la próxima década en la región.

\section{La esfera ciclópica y la única mercancía gratuita}

Asistimos quizás en la actualidad a una turbulencia en el modelo comunicacional vigente. En las tres últimas décadas se 
ha venido gestando un nuevo modelo comunicacional y tecnológico en el que casi la totalidad de la información está digitalizada, hablamos de un lenguaje universal que puede migrar de un lugar a otro en segundos. Esta información es poder para quien la gestione, y quien tiene ese poder, construye las reglas del juego en nuestra realidad.

El flujo de información moderna a nuestro parecer ha sido diseñado para tener una velocidad que arrolle al espectador, quien no dispone del tiempo necesario para reaccionar, discernir o interpretar todos sus contenidos. El efecto que tiene esta velocidad en ese espectador es que consume acríticamente sin reflexionar, y acríticamente sueña con un futuro alejado de sus posibilidades y fuera de su alcance. Se podría decir que sueña con el rico que un día será y se proyecta socialmente como tal y no lucha con los trabajadores, asalariados como él.

El flujo de información actual ha sido calificado por Ignacio Ramonet (2003) como una esfera ciclópica, una unión indiferenciada y acrítica de la comunicación, la información y la propaganda. Hoy por hoy, según Ramonet (2012) existe una sola mercancía gratuita en nuestro tiempo y ésa es la información. Sin embargo cabe hacerse la siguiente pregunta: estando el sistema tan preocupado por los beneficios, por qué ofrece una mercancía gratuita?

A simple vista nos parece que el negocio del poder mediático está en la oferta de información, en ofrecer información a la gente, a nosotros. En realidad consiste en vender grupos de potenciales consumidores a los anunciantes, a las grandes transnacionales. Cuando consumimos información (gratuitamente), estamos siendo reclutados y luego ofrecidos a esas transnacionales que nos venden objetos y servicios. Para que esta lógica funcione, los grupos de potenciales consumidores tienen que ser numerosos, de esta manera obtienen una cuantiosa ganancia.
Otro elemento esencial para que la lógica del poder mediático funcione, la información debe ser superficial, muy básica, con el fin de facilitar su amplia circulación. Según Castells (2009), de los 40.000 vocablos que tiene el castellano, el poder mediático sólo utiliza entre 600 y 800 vocablos.

De igual manera, se necesita que la información esté diseñada con una lógica bilateral (maniquea): o bueno o malo, o blanco o negro; una información deshidratada de su normal complejidad y de sus matices, es como desarrollar una idea en blanco y negro, sin proyección. Para esto, se necesita que esta información posea un fuerte carácter emocional, entendido esto último, como una información fugaz, inmediata y extraordinaria.

En principio, es lógico pensar que nadie invierte en una información que regala y sin inversión, esta información es de baja calidad. Las personas que, por ejemplo, antes poseían la capacidad de leer un artículo de periódico, con la falta de práctica han ido perdiendo esa capacidad acostumbrándose a leer únicamente los titulares de las noticias. Muchas veces se prefieren los textos de tres líneas, sin profundidad, sin advertir la necesidad de reflexión sobre el tema en cuestión, asistiendo con ello a lo que en el ámbito comunicacional se está llamando la twiterizacion de la información, por los 140 caracteres máximo de extensión que permite escribir la red social Twitter.

Existe un creciente interés por las imágenes fugaces, los videos que duran menos de un minuto y los programas de televisión enlatada (importada de los centros de poder mediático hegemónicos) y que no reflejan la realidad de nuestras sociedades, porque no tenemos industria de contenidos, carecemos de producción de contenidos nuevos. Como consecuencia, legitimamos una cultura ajena a nuestras circunstancias, por ejemplo, nuestros niños saben como se llaman las jirafas, los leones y cebras porque desde muy 
pequeños los ven pintados en los muros del preescolar, pero desconocen el nombre del pajarito que se para en el árbol frente a su casa (Peralta,2006).

Esta situación, ha creado un alejamiento progresivo de la radio donde hay que escuchar con atención, para volcarnos en la inmediatez y la superficialidad de la imagen y el video. Como señala Sartori (1998), se está viviendo una migración de la cultura escrita propia del Homo Sapiens a una nueva naturaleza, que él denomina "Homo Videns", caracterizada por un predominio de la cultura audiovisual.

\section{El poder mediático y el Gobierno Mundial}

Esta situación está a la raíz de la crisis editorial de producción de periódicos y libros a nivel mundial, que no tiene más remedio que alinearse y dejar de invertir en información de alto contenido y calidad y "Lo que no existe en los medios, no existe en la mente de los pueblos" (Castells,2011) y en este escenario perdemos todos, porque desde nuestro punto de vista, la opinión pública es el sistema nervioso de cada pueblo, desde el cual se generan nuevas ideas, opiniones concretas y luego acciones de masa protagonizando las transformaciones históricas, desde donde se construye la inteligencia social.

Si por un lado a nivel global la información se vacía de su contenido racional y conceptual, se vuelve más superficial, paralelamente la educación superior no obstante los esfuerzos de algunos gobiernos, gremios y sindicatos de reivindicar la educación gratuita y de calidad como un derecho inalienable, sigue a nivel global la ruta de la privatización, es decir el saber se convierte en un privilegio para los pocos que pueden pagarlo.

El resultado es la desmovilización de la conciencia y una privatización de la inteligencia social, del acceso a las mayorías al saber formal, de su participación activa en la discusión de temas como la política, la economía, el comercio, y otros, que son accesibles y se debaten a partir de el manejo de categorías y conocimientos formales más allá de los saberes populares y originarios. Esta situación ocasiona el empobrecimiento del pensamiento critico y de la conciencia social y como afirma Manuel Castells, hace parte de una estrategia global ya que "la manipulación de las mentes es mucho mas eficaz que la tortura de los cuerpos" (Castells,2011).

En este sentido como apunta Wallerstein, la industria mediática se concibe en la actualidad como un aparato ideológico creado con el objetivo pedagógico de darle legitimidad al Gobierno Mundial y es parte de un modelo llamado por Immanuel Wallerstein Sistema Mundo (Wallerstein,1974) ${ }^{1}$.

Este gobierno mundial está conformado por una serie de multimillonarios, el 1\% que posee el $48 \%$ de la riqueza global, 92 personas con mas de mil millones de dólares, 128,000 personas que poseen más de cincuenta millones de dólares (OXFAM,2014). Esta clase de multimillonarios junto a una serie de instituciones como el complejo militar industrial, su brazo armado la Organización Transatlántica del Atlántico Norte OTAN que hace la guerra pregonando la paz, el sistema financiero, las transnacionales $y$ el poder mediático a sus servicios, que da legitimidad política y cultural al todo.

1 El Sistema Mundo según su autor posee tres ejes articuladores principales, en primer lugar, un sistema económico integrado a nivel mundial de naturaleza polarizadora con una lógica de cadenas de mercancías que poseen una forma centrípeta. En segundo término un sistema político basado en estados soberanos independientes jurídicamente pero vinculados a través de un sistema interestatal y por último un sistema cultural que es capaz de dar coherencia y legitimidad al todo y es denominado Geocultura 


\section{¿Relación entre letra y poder?}

Un sacerdote y pedagogo llamado Lorenzo Milani, decía que "El que sabe mil palabras hará hacer lo que quiera, al que sabe quinientas".

Un concepto útil para analizar esta estrecha relación entre letra y poder lo propone el uruguayo Ángel Rama. Él habla de una Ciudad Letrada (Szurmuk, Mckee 2009), de un círculo de intelectuales ligados al poder que funcionan como un anillo protector y ejecutor de las órdenes de una élite desde la colonia hasta nuestros días. Afirma que el poder del signo y de la palabra es tal, que no representa lo real sino que lo crea (idem), en la misma forma en la que los imperios construyen hegemónicamente y geoculturalmente la realidad.

Durante los últimos 500 años en Nuestramérica este círculo de letrados ha administrado la tecnología de la letra y su funcionamiento, que está a la base de su poder y su prestigio, a través de afirmaciones que comúnmente se utilizan en ámbito académico en Nuestramérica como "lo que no está escrito no existe" no basta que esté dicho o solamente imaginado.

Con la alfabetización la memoria escritural excluye la imaginación y la organización no lingüística del conocimiento y de este modo subalternizan todos los saberes originarios y populares porque son prevalentemente orales y los tildan de inferiores por ser organizados bajo otra lógica.

La Ciudad Letrada para conferir legitimidad y perdurabilidad a su hegemonía crea una separación radical entre incluidos y excluidos de ese conocimiento formal y esa legitimidad se asienta en la inexistencia presunta de excluidos en un proceso de ocultación, de pública ficción.

El resultado es que en nuestro tiempo conviven dos epistemologías y dos cosmovisiones en tensión dialéctica, una cosmovisión hegemónica a la que corresponde una historia, una memoria oficial y un conocimiento formal. Y como su opuesto, una cosmovisión subalterna, a la que corresponde una tradición oral, una historia no oficial, y una sabiduría autóctona popular.

La racionalidad científica moderna occidentocéntrica es totalitaria, en la medida que niega el carácter racional de todas las formas de conocimiento que no se someten a sus principios epistemológicos y a sus reglas metodológicas, a sus formas de entendimiento y explicación de la realidad a su cosmovisión científica.

Esas ausencias (De Sousa Santos,2010) tienen que ser visibilizadas, transformar en objetos posibles los imposibles, las ideas ausentes en presentes, restituir visibilidad a lo ocultado a través de discursos científicos neutrales con una ambigüedad calculada.

Existe lo científico versus lo ignorante: La monocultura del saber, la transformación de la ciencia moderna y de la alta cultura en criterios de verdad y cualidad estética, todo lo que el canon no reconoce por no poseer rigor científico, es declarado inexistente asumiendo la forma de ignorancia e incultura (De Sousa Santos, 2010).

Luego está lo avanzado versus lo residual. La tiranía del tiempo linear (Di Meglio,1997), la idea según la cual la historia tiene un único sentido y única dirección conocida, formuladas con diversas estéticas en los últimos 200 años, que coinciden con las teorías sistémicas: evolucionismo, modernización, desarrollo-subdesarrollo, neoliberalismo. El tiempo lineal y su tiranía produce no existencia, declarando atrasado todo lo que según esa norma temporal es asimétrico en relación a lo declarado avanzado, invisibilizando los intentos de reescritura de la historia y la construcción de relatos historiográficos desde otras cosmovisiones, 
desde otras formas de comprender y explicar el mundo, desde otros sentidos comunes.

Lo superior versus lo inferior como lógica de la clasificación social, la naturalización de las jerarquías como raza y sexo, la normalización de la relación jerárquica de dominación es la consecuencia de la inevitable condición superior y civilizadora del hombre blanco occidental, ante la inferioridad del resto que no es capaz de construir una alternativa creíble frente a esa superioridad, de este modo los pueblos originarios, los países periféricos en el sistema económico mundial vienen calificados como subdesarrollados, junto a sus ciudadanos que vienen clasificados como inferiores.

La productividad versus lo estéril. La lógica productivista donde el crecimiento es un objetivo racional incuestionable, la productividad es el criterio que mejor se apega a este objetivo y se aplica tanto a la naturaleza como al hombre, viendo a la Madre Naturaleza como un medio de producción con una visión mecanicista y abiótica de la producción de alimentos.

Lo global versus lo local: La lógica de la escala dominante que determina la irrelevancia de todas las escalas posibles ante la escala universal, lo local esta aprisionado en escalas incapaces de trascender a su contexto, se naturaliza a través de esta dicotomía la superioridad de lo global, de la globalización y de sus características y sus consecuencias.

Y por último, el criterio que es meta-teórico, y epistemológico, que reúne a los demás y trasciende mas allá de las teorías, que es lo lógico versus lo ilógico: Es transdisciplinario y tiene una trascendencia filosófica y encierra todas las demás categorías definiendo ontológicamente que es la verdad y que es falso o errado. Todas estas dicotomías y en particular la ultima separa lo presumiblemente lógico de lo presuntamente ilógico subalternizando los saberes, las epistemologías y las cosmovisiones originarias, locales contextuales, ante el conocimiento formal, con una lógica occidentocentrica.

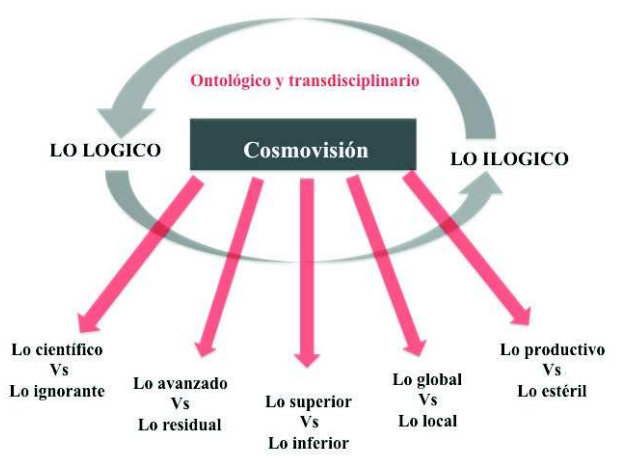

Durante los últimos cinco siglos la sabiduría autóctona nuestramericana ha resistido a un epistemicidio, hemos sido victimas de un homicidio epistemológico de nuestros saberes autóctonos, durante cuatro momentos históricos claves: La colonización, que tuvo su continuidad en las reformas borbónicas, seguida por la Independencia y se concretizó en las Reformas Liberales, con la construcción de los estados nacionales con un carácter monoétnico y el contrato social liberal y más recientemente neoliberal.

Pero si intentamos construir nuestra emancipación por reacción a esta injusticia histórica no llegaremos muy lejos. En nuestro parecer, la clave no debería estar basada en el rencor o el odio histórico, debería estar alejada de ese proceso de re-victimización.

\section{Cartografía del poder mundial generadora de un nuevo saber emancipador}

Tal vez esa segunda independencia hacia la que caminamos en materia de construcción de un saber emancipatorio y liberador, pasa a través de la construcción de epistemologías múltiples que nacen de un sinnúmero de experiencias humanas, saberes originarios, locales, comunitarios contextualizados, que nacen de la vida diaria de los pueblos y se legitiman como parte de una red semántica 
de significados cultural y geopolíticamente situados, que nos permita reorientar la producción, circulación y el consumo del conocimiento y así pensar nuestra realidad a partir de nuestras circunstancias históricas. Es necesario localizarnos geopolítica, geoeconómica y geoculturalmente desde donde producir nuevo conocimiento.

Podríamos considerar que estamos inmersos en una migración del Neoliberalismo hacia el Posneoliberalismo, al mismo tiempo que estamos viviendo un tránsito del unipolarismo que dominó la escena geopolítica global durante dos décadas, hacia un mundo donde quepan muchos mundos, un multipolarismo naciente, a raíz de las luchas de los pueblos por su liberación, junto al agotamiento del modelo neoliberal: Por otra parte, también se aprecia una creciente pérdida de poder y legitimidad de los Estados Unidos y Europa a partir de la crisis financiera del 2007-2008. Unida al creciente protagonismo político y económico de Rusia y China, así como de otros grupos económicos como los BRICS (Brasil, Rusia, India, China y Sudáfrica) el G77+China y otros situados en Asia y Oriente.

Este panorama geopolítico delineado líneas arriba, podría completarse con el surgir de una nueva geopolítica del Sur que propone una nueva dimensión económica, social $\mathrm{y}$ ambiental y una nueva democracia y arquitectura financiera.

Nicaragua se encuentra entre dos fuerzas contrarias representadas por dos triángulos: Un triángulo que batalla por nuestra emancipación, conformado por el ALBA-TPC que construye una nueva forma de soberanía política y económica, PETROCARIBE que brinda seguridad energética a los países que hacen parte y la CELAC, que batalla por la soberanía económica y política del continente al sur del rio Bravo, en la hoja de ruta de la segunda independencia.
Por el otro lado se encuentran La Alianza del Pacifico, promovida por los Estados Unidos, como parte de una estrategia de construcción de una nueva hegemonía en el pacifico que junto a la Alianza del Pacifico ha propuesto y actualmente aprobado la Asociación Transpacífica TPP conformada por 11 países ubicados en los entornos costeros del pacifico (Japón, Australia, Nueva Zelanda, Malasia, Brunei, Singapur, Vietnam, Canadá, y los latinoamericanos México, Perú y Chile) que abarcan un tercio del comercio global y el $40 \%$ del PIB mundial, creado entre otros motivos, con la intensión de socavar la creciente influencia de China en sus entornos limítrofes.

Paralelamente las élites económicas de ambos lados del atlántico, Estados Unidos y Unión Europea están negociando otro tratado comercial, la Asociación Transatlántica de Comercio e Inversión TTIP, el primer tratado de libre comercio del Siglo XXI entre potencias, con una población de 800 millones de personas y la mitad del PIB mundial.

Estos tres tratados de libre comercio, pujan por la predominancia del Gobierno Mundial, tienen el objetivo de promover la gobernanza corporativa y el predominio de las transnacionales sobre la soberanía de los pueblos y los estados nacionales independientes políticamente. El reequilibrio de las fuerzas geopolíticas y geoeconómicas a nivel global, abre un periodo de grandes oportunidades para los pueblos en su lucha por la emancipación, en su lucha por la justicia cognitiva, como acceso al saber desde una posición más igualitaria, intercultural y democrática. Las coordenadas trazadas líneas arriba nos permiten enfocar la cartografía del poder mundial.

Desde esa correlación de fuerzas geopolíticas, geoeconómicas y geoculturales; desde esa lucha dialéctica entre regulación y emancipación denuestros pueblos generamos nuestras reflexiones, construimos nuevos saberes, pero a su vez cada uno de nosotros 
construye desde sus circunstancias históricas y personales, desde su autobiografía, su historia personal, sus valores y sus aspiraciones y desafíos como revolucionario, como intelectual orgánico (Gramsci,1967), a la vez que lucha por la recuperación de su memoria histórica, por el legado dejado por los luchadores que nos antecedieron, y mira hacia su horizonte buscando un futuro más justo, buscando la anticipación de ese tiempo nuevo que llegará, con la mirada en la utopía, con el firme convencimiento que merecemos un futuro mejor para nosotros en comunión con la Madre Tierra.

En lo profundo de nuestras raíces originarias buscamos el Buen Vivir como exigencia éticopolítica, como un modo de vida en la acción, en reciprocidad, yo soy si tu eres (Dussel,1996) como un paradigma que estuvo antes de la modernidad, esta presente ahora y tiene la capacidad de trascender a la modernidad, con sus tres principios: No robar, porque anti-comunitario, anti-solidario; No mentir, porque no hay que traicionar a la comunidad, a la familia y No dejar de trabajar, no dejar de crear comunitariamente en comunión con la Madre Tierra. Y por ultimo el antiimperialismo nuestramericano que nos define como luchadores y como pueblo que reivindican su soberanía, soberanía política así como su soberanía semántica.

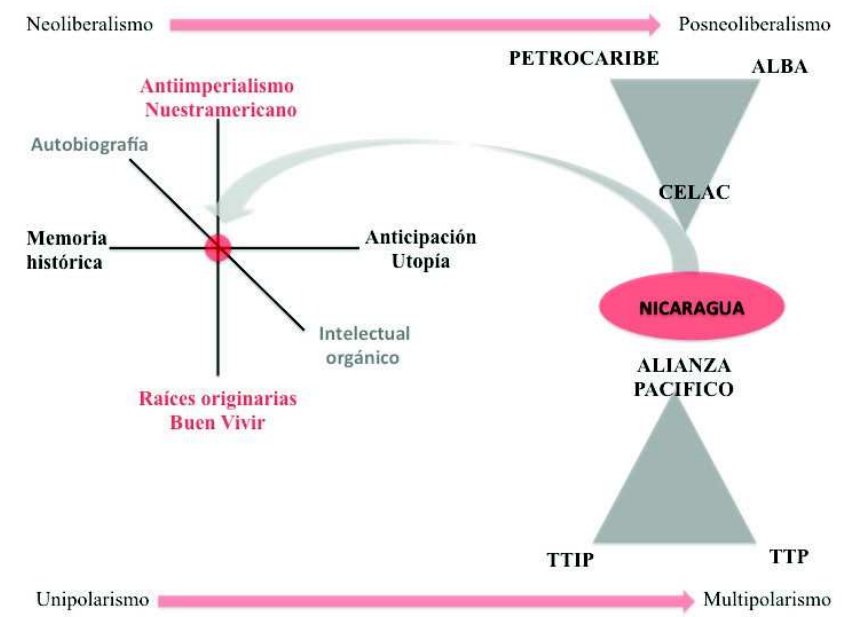

\section{Conclusiones}

La justicia global pasa por la justicia cognitiva (De Sousa Santos, 2010) y esta por la construcción de un conocimiento emancipador representado en el poder político. Esta conjunción global de la justicia, es capaz de mover a los pueblos ante su realidad en esta batalla de las ideas.

El nuevo reto, luego de haber transitado de la energía social a la toma del poder político, pasa por la construcción de un bloque hegemónico (Gramsci, 1967) de la conciencia del pueblo para decidir su futuro, para transformarse en sujeto histórico y protagónico de su espacio y de su tiempo, a partir de esa fuente de energía de saberes que germinan y habitan en su seno. Energía saber transformada en nuevas capacidades, acciones, inteligencia social, lucha continua por revolucionar la conciencia; construir y rescatar valores que nos enrumban hacia el bien común y a nuestra sobrevivencia como especie.

Esta batalla de ideas se juega alrededor del conocimiento que da conciencia, libertad de acción y libertad de decisión, para construir el poder del pueblo, desde el pueblo. Se transita así, de esa energía-saber, a la inteligencia social, revolucionaria y autóctona, como la progresiva construcción de un liderazgo político-cultural general, de una lucha por revolucionar el sentido común más intimo y profundo de la persona, la familia, la comunidad y la nación.

La inteligencia social es revolucionaria porque se pone en discusión a sí misma. Es capaz de transformarse con el fin de responder a sus propias circunstancias históricas. A su vez es intercultural porque apunta al objetivo de crear un puente revalorador entre la sabiduría autóctona y el conocimiento formal. Es comunitaria, porque se dirige hacia el bien común tejiendo lazos de comunión entre la comunidad donde se pone en praxis. 
Es Autóctona, porque es nuestramericana, creativa y originaria, se mueve en el territorio simbólico del sentido común, que atraviesa esa realidad comunitaria contextualizada sin imponer pedagogías ajenas al contexto en el cual se construye.

Se trata de la capacidad de anticipación, de observación profunda y empática de la formación de los valores, de la formación de identidades desde las más cristalizadas y concretas hasta las más versátiles y magmáticas. Es una inteligencia popular que observa con atención la génesis de los cambios e intercepta las transformaciones sociales y las protagoniza; se apropia del saber para construir el poder y del poder para construir el saber.

\section{Referencias bibliográficas}

Castells, M. (2009). Comunicación y Poder. Madrid, España: Alianza Editorial.

Castells, M. (2011). Poder y Comunicación Acampada Barcelona 2011. publicado el 06 de mayo 2011 en WWW.youtube. com Acceso: https://www.youtube. com/watch? $=i$ iUsNhz9Vxkk

De Sousa Santos, B. (2010). Descolonizar el saber. Reinventar el poder. Uruguay: Ediciones Trilce.

Di Meglio, M. (1997). Lo sviluppo senza fonadamenti. Trieste Italia: Asterios Editore.

Dussel E. (1996). Filosofía de la liberación. Bogotá: Editorial Nueva América.

Gramsci, A. (1967). La formación de los intelectuales. México: Editorial Grijalbo.

Oxfam, (2014). Iguales, Acabemos con la desigualdad extrema, es hora de cambiar las reglas. Publicado en enero 2014: https://www.oxfam. org/sites/www.oxfam.org/files/file attachments/cr-even-it-up-extremeinequality-291014-es.pdf

Peralta, M. V. (2006) “En la educación nos jugamos el futuro" No290 Mayo 2006.
Ramonet, I. (2003). “El quito poder" Le Monde Diplomatique N`7 Octubre 2003.

Ramonet, I. (2012). Fidel Castro con los intelectuales, Nuestro deber es luchar. La Habana Cuba: Editorial José Martí.

Sartori, G. (1998). Homo Videns, La sociedad teledirigida. Buenos Aires Argentina: Editorial Alfaguara.

Szurmuk, M. Mckee, R. (2009) Diccionario de estudios culturales latinoamericanos, México, Siglo XXI Editores.

Wallerstein, I. (1974) The modern World System I: Capitalist Agriculture and the Origins of the European World-Economy in the Sixteenth Century. New York: Academic Press. 